\section{Adrenergic and cholinergic drug effects on retention of a discriminated escape*}

\author{
THOMAS C. MADDEN, JR. and WILLIAM T. GREENOUGH \\ University of Illinois, Urbana/Champaign, Ill. 61820
}

Rats were trained in a discriminated Y-maze escape task. At $1,3,7$, or 28 days after training, an injection of eserine, amphetamine, chlorpromazine, or saline was given and the rats were retrained. Eserine and chlorpromazine animals showed better retention than saline controls, particularly 1 day after training. Amphetamine enhanced retention at 1 day, but performance deteriorated in groups tested at longer intervals. These results do not agree fully with other experiments and suggest that drug-induced changes in retention may involve central activation levels as well as retrieval processes.

Deutsch has proposed that alterations in the neurotransmitter acetylcholine $(\mathrm{ACh})$ at selected synapses may underlie long-term memory. This theory is supported by experiments with cholinergic drugs at various time intervals after learning. Deutsch, Hamburg, \& Dahl (1966) and Deutsch \& Leibowitz (1966) found that di-isopropyl fluorophosphate (DFP), an anticholinesterase, caused a deficit in performance when injected 5 or 14 days after training but improved performance if injected at 28 days. Hamburg (1967) found the deficit at 5,7 , and 14 days with another anticholinesterase, eserine. Deutsch and Rocklin (1967) found that scopolamine, an anticholinergic, impaired memory 1 and 3 days after training but had no effect at 7 or 14 days. Deutsch \& Deutsch (1966) postulated that maximal release of ACh corresponds to maximal memory strength and subsequent decline of ACh release corresponds to forgetting. When ACh release is low, either before or after maximal memory strength, DFP and eserine enhance memory; when $\mathrm{ACh}$ release is high (e.g., 5 to 14 days after training), anticholinesterases impair memory by causing synaptic blockage. Scopolamine has the opposite effect.

The effects on long-term retention of adrenergic drugs, such as chlorpromazine (CPZ) and amphetamine, have not been examined. $\mathrm{CPZ}$ is an adrenergic blocking agent (Carlsson, 1967), and amphetamine potentiates the action of norepinephrine (NE) (Hanson, 1967). Thus their effects on adrenergic transmission are analogous to those of

* This report is based on a MA thesis submitted by the first author to the graduate college of the University of Illinois, Urbana-Champaign. The work was supported by the University of Illinois Research Board. Reprints may be obtained from the second author, Department of Psychology, University of Illinois, Champaign, Ill. 61820 . scopolamine and DFP on ACh. CPZ has effects similar to anticholinesterase and cholinomimetic drugs in some behavioral situations (Chalmers \& Erickson, 1964; Goldberg \& Johnson, 1964), and eserine has been found to antagonize amphetamine effects in a nondiscriminated avoidance situation (Goldberg \& Ciofalo, 1969). Carlton ( 1963 ) has postulated a two-component process in which an $\mathrm{NE}$ system is responsible for behavioral activation and an $\mathrm{ACh}$ system inhibits or possibly channels this activation. If the effects obtained by Deutsch and his coworkers involve activation processes, then CPZ, which inhibits $\mathrm{NE}$-mediated activation, and eserine, which enhances $\mathrm{ACh}$ inhibition of activation, might have similar effects. By the same reasoning, effects of amphetamine should be opposite those of both eserine and CPZ.

\section{SUBJECTS}

The Ss were 146 male Long-Evans hooded rats, 90-140 days old at the time of training. All animals were housed individually in stainless steel cages and given free access to food and water.

APPARATUS
Training and retraining were carried out in a $\mathrm{Y}$-maze placed in a darkened room. Each arm of the maze was $50 \mathrm{~cm}$ long and $16 \mathrm{~cm}$ wide, with black Plexiglas walls $24 \mathrm{~cm}$ high. The floor consisted of steel bars $1.3 \mathrm{~cm}$ apart. The end wall of each arm contained a cue light ( $24 \mathrm{~V}, \mathrm{GE} 1829$ ) mounted $12.5 \mathrm{~cm}$ above the grid floor. A .04-W shock was delivered to the grid floor by a BRS-Foringer SGS-001 shock scrambler. When the rat was in the maze, the center section was always electrified; the terminal $16 \mathrm{~cm}$ of an alley was shock-free only when the light in that alley was turned on. PROCEDURE

The Ss were trained to escape shock by running to the lighted arm of the Y-maze. After 5-15 min of dark adaptation, the $\mathrm{S}$ was dropped into a dark electrified arm of the Y-maze and continued to receive shock until he reached the shock-free grid in the lighted alley. After $60 \mathrm{sec}$, the light in the occupied alley was turned off and the shock was turned on; simultaneously, another alley was lighted and the shock grid turned off. An incorrect response was scored if the animal entered the last $24 \mathrm{~cm}$ of the dark alternative alley. The sequence of lighted alleys followed a semirandom order, with no more than three consecutive left or right turns.

The Ss were trained to a criterion of 9 out of 10 correct responses, and only those rats who had begun a criterion series between the 9 th and 80 th trials were retained. Immediately after training, each rat was returned to his home cage and remained there until the assigned test day. Initial training scores were counterbalanced across groups.

At intervals of $1,3,7$, or 28 days after training, independent groups of Ss were weighed and injected intraperitoneally with eserine (physostigmine salicylate, $0.5 \mathrm{mg} / \mathrm{kg}$ of body weight), CPZ (chlorpromazine hydrochloride, $1.5 \mathrm{mg} / \mathrm{kg}$ ), amphetamine (amphetamine sulfate, $2.0 \mathrm{mg} / \mathrm{kg}$ ), or the physiological saline vehicle. Thirty minutes after injection, each animal was placed in the maze and tested as before. Retention was measured by the number of correct responses made during 10 trials of retraining.

\section{RESULTS}

Thirty-four Ss failed to meet criterion within the prescribed limits. One animal (eserine group at 28 days) was injured during testing, so there were six scores for that group and seven for all others. Figure 1 presents the mean number of correct responses in 10 trials at the various training-injection intervals for saline, eserine, CPZ, and amphetamine groups.

Analysis of variance revealed a significant overall drug effect $(\mathrm{F}=3.349, \mathrm{df}=3,95, \mathrm{p}<.025)$. Both eserine and $\mathrm{CPZ}$ groups were superior to saline controls across all days by the Duncan multiple-range test $(\mathrm{p}<.05)$. Whereas saline groups scored a mean of 7.4, eserine groups scored a mean of 8.6 and $\mathrm{CPZ}$ groups scored a mean of 8.3. The Duncan test at individual days indicated that eserine, CPZ, and amphetamine at 1 day all significantly improved performance $(p<.05)$ and that eserine at 7 days also improved performance over that shown by 7 -day saline controls $(p<.05)$. However, at 28 days, the amphetamine group suffered significant impairment in relation to eserine and $\mathrm{CPZ}$ groups $\mathrm{p}<.05)$. Other differences at 3 - and 
7-day intervals were not significant. There was also a linear trend toward poorer performance across days for the amphetamine groups $(F=4.27$, df $=24, p<.05)$.

\section{DISCUSSION}

The results of this experiment are not entirely in agreement with those of Hamburg (1967). At 7 days after training in the Hamburg study, eserine had a significant amnesic effect. In the present study, eserine-treated rats showed excellent retention after 7 days, while the training procedures were similar to those of Hamburg. In fact, at none of the time points sampled was the retention of the eserine group worse than that of saline controls.

The similarity of the effects of eserine and CPZ (Fig. 1) supports the notion that antagonistic activation systems, as postulated by Carlton (1963), may influence the performance of a learned task. Rats trained in the $\mathrm{Y}$-maze received extensive periods of footshock. Hence, activation level may be very high $24 \mathrm{~h}$ after training; performance, or retention, is then poor because activation is nondirectional, and all responses, even incorrect ones, are facilitated equally. Administration of CFZ lowers activation; this increases the probability that the previously reinforced response will occur, as there is less "background noise." Similarly, eserine increases cholinergic antagonism of incorrect responses (activation) in the Carlton model and enhances the probability of the correct response.

Injection of amphetamine 1 day after training would be expected to raise an already high level of activation. In fact, amphetamine may actually lower activation in this case. Ladisich, Volbehr, \& Matussek (1970) found that amphetamine antagonized drug-induced hyperactivity in rats in much the same manner as it works to reduce hyperactivity in children. They postulated that amphetamine causes a build-up of normetanephrine at adrenergic synapses, such that synaptic blockage occurs. This reversal of

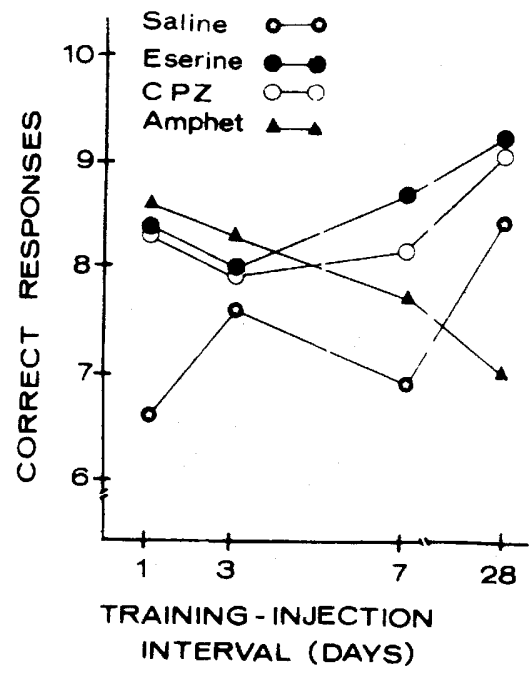

Fig. 1. Mean number of corrent responses during the first 10 trials of retraining for different drug treatments at various training-injection intervals.

amphetamine effect is similar to the action of DFP or eserine in blocking cholinergic synapses, as proposed by Deutsch. Thus, the improved retention with amphetamine treatment at 1 day may also be due to decreased activation.

At 28 days, amphetamine caused significant impairment. It is possible that, by this time, activation level has substantially subsided and amphetamine acts to raise activation level so high that performance is poor. Retention shown by the Ss on the first test trial supports the notion that the drug effects are not on memory per se. On the first trial, all groups, except the 1-day saline group, showed a preference for the correct (lighted) arm of the maze. On this measure, the 28-day amphetamine group showed no retention deficit, but performance on subsequent trials was very poor.

This interpretation must be considered tentative, since this appears to be the first examination of the effects of amphetamine and CPZ on performance of such a task learned days or weeks earlier, and no data is available for comparison. Furthermore, the results obtained with eserine are not in agreement with results obtained by Deutsch and coworkers. Different dosage levels of both cholinergic and adrenergic drugs and different time intervals may help. to define the relation of activation level to apparent retention.

\section{REFERENCES}

CARLSSON, A. Basic actions of psychoactive drugs. International Journal of Neurology, 1967, 6, 27-45.

CARLTON, P. L. Cholinergic mechanisms in the control of behavior by the brain. Psychological Review, 1963, 70, 19-39.

CHALMERS, R. K., \& ERICKSON, C. R. Central cholinergic blockade of the conditioned avoidance response in rats. Psychopharmacologia, 1964, 6, 31-41.

DEUTSCH, J. A., \& DEUTSCH, D. Physiological psychology. Homewood, III: Dorsey Press, 1966.

DEUTSCH, J. A., HAMBURG, M. D., \& DAHL, H. Anticholinesterase induced amnesia and its temporal aspects. Science, 1966, 151, 221-223.

DEUTSCH, J. A., \& LEIBOWITZ, S. F. Amnesia or reversal of forgetting by anticholinesterase, depending simply on time of injection. Science, 1966, 153, 1017-1018.

DEUTSCH, J. A., \& ROCKLIN, K, W Amnesia induced by scopolamine and its temporal variations. Nature, 1967, 216 , 89-90.

GOLDBERG, M. E., \& CIOFALO, V. B. Alteration of the behavioral effects of amphetamine by agents which modify c holinergic function. Psychopharmacologia, 1969,14 , $142-149$.

GOLDBERG, M. E., \& JOHNSON, H. E. Behavioral effects of a cholinergic stimulant in combination with various psycho-therapeutic agents. Journal of Pharmacology \& Experimental Therapeutics, 1964, 145, 367-372.

HAMBURG, $M$. D. Retrograde amnesia produced by intraperitoneal injection of phy sostigmine. Science, 1967, 156, 973-974.

HANSON, L. C. F. Evidence that the central action of $(+)$ - amphetamine is mediated vi a catecholamines. Psychopharmacologia, 1967, 10, 289-297.

LADISICH , W., VOLBEHR, H., \& MATUSSEK, N. Paradoxical effect of amphetamine on hyperactive states in correlation with catecholamine-metabolism in brain. In E. Costa and S. Garattini (Eds.), Amphetamines and related compounds. New York: Raven Press, 1970. Pp. 487-492. 